\title{
DEUS E O DIABO NA TERRA: cidades como espaços possíveis das práticas desviantes
}

\author{
Msc. Avacir Gomes dos Santos \\ Doutoranda do Programa de Pós-Graduação em Geografia do IESA/UFG \\ Rua Área Verde, Q. 55, L 01, Casa 02, Conjunto Itatiaia II, 74.690-460, Goiânia (GO)-Brasil \\ Tel (5561)3399.6523 - avagsantos@yahoo.com.br \\ Prof $^{\mathrm{a}}$. Dr ${ }^{\mathrm{a}}$. Maria Geralda de Almeida \\ Bolsista Produtividade CNPq \\ mgdealmeida@gamail.com
}

\section{RESUMO}

A cidade é o espaço da tese e síntese do capital. A organização econômica e a configuração espacial são fundantes para funcionalidade, expansão, manutenção e inovação capitalista. Destarte, a cidade é significada apenas como espaço coisificado do mundo do trabalho. Porém, o capital formata sua própria antítese, a qual é apresentada no espaço vivido por meio de práticas desviantes. Práticas e espacialidades desviantes dizem respeito a comportamentos, atitudes, gestos, linguagens e pensamentos que se desviam das lógicas planejadas para comercialização do espaço. Escrevemos sob a relação entre cidade e práticas desviantes em três puctuns. Partimos da abordagem cultural para pensar a cidade no interstício dos níveis de produção social do espaço. Em seguida, realizamos um exercício hermenêutico a favor e contra a cidade para caracterizá-la como espaço por excelência das diferentes espacialidades. Por último, exemplificamos as práticas desviantes como elemento antitético do capital. Defendemos que, as práticas desviantes causam o mal estar da civilização ao materializar a existência de espacialidades possíveis fora da lógica de configuração do espaço ditada pelos grupos e atores hegemônicos.

Palavras-chave: Cidade, práticas desviantes, espaço percebido, espaço concebido e espaço vivido.

\begin{abstract}
The city is space of the thesis and synthesis of capital. Economic organization and the spatial configuration are founding for functionality, expansion, maintenance and capitalist innovation. Thus, the city is meant just as objectified space of world of work. However, capital formats your own antithesis, which is presented in the lived space through of deviate practices. Practices and deviant spatialities relate to behaviors, attitudes, gestures, languages and thoughts that deviate from logics planned for commercialization of space. Write in the relationship between city and deviant practices in three punctuns. We start from the cultural approach to think the city in the interstitial levels of social production of space. Then, we realize a hermeneutic exercise in favor and against the city to characterize it as a place for excellence in different spatiality. Finally, we exemplify the deviant practices as antithetical element of the capital. We believe that the deviant practices cause discomfort of civilization to realize the existence of spatialities possible out of the logic of space configuration dictated by hegemonic actors and groups.
\end{abstract}

Key Words: City, deviant practices, perceived space, conceived space and lived space.

\section{RÉSUMÉ}

La ville c'est l'espace de la thèse et la synthèse du capital. La organization économique et la configuration spatial sont fondants four fonctionnalité, expansion, manutention et innovation capitaliste. Ainsi, la ville est signifié seulement comme espace-chose du monde de travail. Mais, le capital forme sa même antithèse laquelle c'est presenté dans espace vécu à travers pratiques detournantes. Pratiques et spatialités detournantes signifient conduites, attitudes, gestes, langages et pensées lesquels se detournent des logiques projetés pour commercialisation du espace. Nous écrivons sur la relation entre ville et pratiques detournantes en trois punctum. Nous initions de la abordage culturel pour penser la ville dans interstice des niveaux de la production sociale du espace. Ensuite, réalisons un exercice herméneutique favorable et contraire à ville pour caractériser la ville comme espace, par excellence, des différentes spatialités. Par final, exemplifions les pratiques detournantes comme élément antithétique du capital. Nous soutenons que les pratiques detournantes occasionnent le malaise de la civilisation par matérialiser la existence de spatialités possibles hors de la logique de configuration du espace dictée par groupes et acteurs hégémoniques.

Mots-Clés: Ville, pratiques detournantes, espace perçu, space conçu et espace vécu

\section{INTRODUÇÃO}

Um dos espaços mais estudado, poetizado, quantificado, desejado, odiado, amado, temido, pesquisado, evitado, procurado, planejado, coisificado, repudiado, negociado e aplaudido tem sido a cidade. A produção da cidade como apresentada na atualidade é resultante do advento da industria- 
lização e do urbanismo, que promoveram organizações até então não experienciadas e vivenciadas nas anteriores formas espaciais: cidade política, cidade mercantil e a cidade industrial.

A cidade se multiplica nas várias dimensões do espaço: percebido, concebido e vivido. Esses, interligados e interdependentes se constituem em lógicas integradoras e diferenciadas. Nessa dinâmica incessante, silenciosa, violenta e inaudível as isotopias e heterotopias revelam as estratégias e táticas de domínio e apropriação dos espaços, presentes nas práticas desviantes dos caminhantes e andarilhos das cidades.

Frente a essa erupção de objetividades e subjetividades como os estudos e pesquisas geográficas podem contribuir para explicar, analisar, interpretar e compreender as diferenciações de sentidos, vivências e práticas espaciais? Qual o método mais adequado para apreender a cidade? Se a opção metodológica implica uma opção teórica, qual teoria se constitui válida para a leitura e compreensão das complexidades dos espaços e práticas desviantes vivenciadas e experienciadas no espaço citadino?

Comecemos então por pensar a cidade. Em "Possíveis discursividades geográficas da cidade", apresentamos nossa proposta teórica para compreensão das conexões presentes nos interstícios do espaço percebido, concebido e vivido. Esta concepção triádica possibilita a interpretação totalizadora do espaço em relação aos aspectos econômicos, sociais, políticos, imaginários, sígnicos e históricos. Partimos do pressuposto básico, o espaço enquanto resultante da produção social.

Teorizar sobre a cidade é nosso ponto de partida. Mas para compreendê-la propomos outros movimentos, o andar pelas ruas, o encontrar pessoas, o ver, o ouvir, o falar e sentir os sons, as cores e os cheiros da cidade. No item: "A cidade: palimpsesto das práticas sociais", desenvolvemos um exercício hermenêutico duplo, que implica perceber a cidade como espaços múltiplos e diferentes, espacializados por intermédio dos passos dos seus caminhantes e andarilhos.

Por fim, em "Práxis urbana: práticas desviantes de espacialidade", partimos do pressuposto das práticas desviantes, como elemento antitético do espaço percebido e concebido capaz de superar as lógicas impostas pelas estratégias de controle e domínio do espaço. Para corroborar o nosso conceito de especialidades desviantes exemplificamos algumas dessas práticas, que são experienciadas e vivenciadas nos espaços da cidade de forma dissimulante e dissimulada.

Neste ensaio procuramos contribuir com as discussões do espaço urbano por meio das primeiras aproximações do conceito de prática desviante. A pretensão é ampliar o debate sobre a cidade e corroborar a idéia da necessidade do geógrafo culturalista se lançar para o mundo vivido, o mundo das pessoas, a vida da cidade, ouvir suas vozes, sentir e provar seus cheiros, andar e desviar dos caminhos, experienciar junto com as pessoas suas inquietudes e angústias cotidianas, enfim animar sua anima. Neste encontro com o outro, acreditamos, nascem possibilidades de visões totalizadoras que podem romper com a lógica da fragmentação dos espaços-tempos, impostas pelos grupos hegemônicos em favor da configuração mecanicista do espaço.

\section{POSSÍVEIS DISCURSIVIDADES GEOGRÁFICAS DA CIDADE}

O movimento pós-moderno experienciado pela filosofia, arte e ciências tem provocado novas formas de concepções sobre o real, natureza e sociedade. O pensamento geográfico também foi agenciado pelo "bonde" das transformações ontológicas e epistemológicas da modernidade. O espaço geográfico, em sua gênese, foi percebido como estruturante, físico, objetificante e objetivado. Na atualidade, o espaço passa a ser concebido como múltiplo, diversificado, híbrido, plural, interconectado e inseparável dos demais elementos contigentes da existência humana.

Por muito tempo a noção de espaço foi permeada na geografia, entre outros elementos, pela idéia de escala. O geógrafo se apropria do espaço por meio do uso da escala. Por exemplo, ao estabelecer análises continentais, climatologia; nacionais, revelo ou hidrografia; regionais, vegetação. Também, a delimitação de grande área de extensão era priorizada em detrimento da pequena área: a 
cidade, o bairro, o quarteirão, a rua. Quanto maior a extensão da área analisada maior era a garantia de valoração das pesquisas geográficas.

A escala geográfica, hoje é entendida muito mais que simples recorte ou instrumentalização de análise científica. Ela está diretamente relacionada com a postura do pesquisador e sua concepção de espaço. Como defende Castro, (2007, p. 136),

[...] escala é a escolha de uma forma de dividir o espaço, definido uma relação percebida/concebida, é uma forma de dar-lhe uma representação, um ponto de vista que modifica a percepção da natureza mesma deste espaço, e, finalmente, um conjunto de representações coerentes e lógicas que substituem o espaço observado.

A escala é o binóculo utilizado pelo pesquisador para esquematizar a complexidade e diversidade de certa área ou realidade geográfica. A escala perceptiva do teórico é reducionista, pois em essência promove um corte empírico enquadrado numa dada paisagem. As vivencias, as lógicas e experienciações do espaço vivido, por não serem propicias aos esquadros, esquemas, gráficos, sistemas de gerenciamento e tabelas, são postas em segundo plano.

Os espaços vividos da cidade quando adentram as escalas, delimitações cartográficas ou levantamentos estatísticos são considerados como partes somatórias para formação do todo. Pensar a cidade, o bairro, a rua, a casa, o lugar é sair à caça da singularidade, é se adentrar nas águas mais profundas e fundantes para além daquilo que aparentemente é percebido por meio da paisagem "natural" e paisagem construída. A cidade é constituída de lógicas. Segundo Claval: "pode-se tentar compreendê-las enfatizando os processos e os mecanismos econômicos ou políticos que tornam indispensável à concentração dos seres humanos." (2008, p. 33). Porém, existem outros caminhos, que agenciados aos fatores econômicos e políticos podem enriquecer a leitura e a interpretação da cidade.

Como aprender, descrever, analisar, interpretar e compreender a cidade a partir das novas orientações teóricas e metodológicas exigidas pelo novo contexto científico? Como captar a complexidade, riqueza, multiplicidades de espacialidades produzidas e reproduzidas na cidade? Que procedimentos são mais significativos para realizar a leitura da cidade? O método dedutivo ou indutivo? Das abordagens positivistas, marxistas e fenomenológicas qual provoca maior aproximação entre as análises geográficas e as espacialidades humanas presentes nos espaços da cidade?

A nossa proposta não é receitual. O que desejamos é pensar as possibilidades de compreensão envoltas nas espacialidades experienciadas e vivenciadas na cidade, por meio da compreensão teórica da abordagem cultural. Partimos do seguinte pressuposto: o espaço é elemento fundante do real. Ele produz e reproduz as relações sociais, econômicas, culturais, simbólicas e imaginárias vivenciadas e experienciadas pelas pessoas em determinado contexto, por meio do movimento constante e incessante, ir e vir, dos caminhos e andarilhos.

Não existe teoria que suplante outra. Concordamos com Foucault (2000), idealismo, positivismo, estruturalismo, marxismo, fenomenologia são formações discursivas elaboradas por meio de percepções diferenciadas daquilo designado como realidade. As teorias proporcionam leituras do mundo e da realidade humana. Elas são produtos sociais, indicam uma concepção de mundo tanto do autor quanto do momento de sua idealização. Apesar das divergências, as teorias apresentam em suas gêneses propostas para superação das idéias até então cristalizadas num determinado contexto geográfico e época histórica.

Qualquer tentativa de enquadrar esta ou aquela teoria é uma pretensão reducionista. Segundo Jenkins, (2001), uma atitude reveladora da cultura ocidental que percebe o mundo por meio dos pareamentos: entre bem e mal; idealismo e materialismo; espírito e corpo; consciência e existência; idéias e mundo, espaço e tempo, como esferas divisíveis. Pelo contrário, essas dimensões da vida se compõem simultaneamente num movimento dialético, incessante e silencioso. 
Feita essa ressalva, reafirmamos: a abordagem que propomos é uma das possibilidades de leitura da cidade. As ciências geográficas não detêm, única e exclusivamente o lócus da "verdade" absoluta sobre o espaço, território, região, ou lugar. Ao geógrafo cabe a busca incansável e apaixonante pelo saber, o conhecimento dos lugares e o envolvimento com as pessoas e suas culturas.

Para pensarmos o espaço enquanto elemento fundante das espacialidades, apresentamos a seguinte fórmula: $\mathrm{E}=\mathrm{EP}+\mathrm{EC}+\mathrm{EV}$, elaborada por Lefebvre, por meio da Teoria Produção do Espaço Social. $\mathrm{E}=$ espaço. $\mathrm{P}=$ percebido. $\mathrm{C}=$ concebido. $\mathrm{V}=$ vivido. Assim, o espaço é a síntese totalizadora dos espaços: percebido, concebido e vivido.

Ao compreender o espaço como resultante da produção das relações sociais Lefebvre (1983, 1991, 2001, 2004, 2008) promove o desdobramento da teoria marxista. Ele relaciona o modo de produção capitalista com a configuração espacial. Esta relação intrínseca entre produção e espaço não fora amarrada pelo genitor do "Capital”. Segundo Harvey (2006, p. 43),

Em parte, isso é conseqüência de uma falha de Marx, pois seus escritos sobre o assunto são fragmentados e, muitas vezes, desenvolvidos apenas de modo superficial. No entanto, o exame atento de suas obras revela que ele reconheceu que a acumulação de capital ocorria num contexto geográfico, criando tipos específicos de estruturas geográficas.

Para Lefebvre, bem como para Harvey, o espaço é, assim como o trabalho e capital, o elemento fundante da produção e reprodução das relações sociais existentes na sociedade capitalista. $\mathrm{O}$ espaço, para Harvey (2006), é organizado socialmente, em primeira instância, para promover a acumulação capitalista, por meio do excedente de mão de obra, meios de produção e mercado consumidor.

O espaço na concepção lefebvriana é constituído em três esferas: percebido, o concebido e vivido Elas estão dialeticamente interligadas, no entanto cada uma possui seu próprio conjunto de signos, significados e significantes. De acordo com Sahr (2007, p. 68), “espaço percebido é vivenciado imediatamente e, às vezes, até fica sem interpretação cognitiva. Forma-se parcialmente contra as vontades dos moradores, baseado em linguagens impostas pelo próprio capitalismo".

O espaço percebido é o lócus da negação, do não-lugar, da coisificação, da heterotopia, da rotina e do desgaste cotidiano. No espaço percebido as relações sociais são esquizofrênicas. O movimento das pessoas, o ir e vir, é vigiado e controlado pelas formas de espacialidades determinantes de horários, espaços e ritmos do trabalho, alienado e alienante. Acorrentado pelas estruturas e formas dos espaços concebido e percebido o ser humano se encontra preso à negação de sua essência. Como nos ensina Sartre (2007), a liberdade é a essência humana. Subjacente às formas de controle de espaço-tempo está o aprisionamento da liberdade e do desejo.

Por meio do espaço concebido se materializam as práticas de isotopia (inclusão) e de heterotopia (exclusão). As ideologias resignificadas pelos planejadores urbanísticos convencem os moradores da cidade sobre os espaços de domínio e espaço "consumidos" coletivamente. De acordo com Lefebvre (2004, p. 10), "em verdade, o que o urbanismo acaba promovendo e legitimando é uma redução da vida urbana ao mínimo". "Proibida a entrada", eis uma das maiores advertências imposta na cidade. Essa é uma imagem arquetipa presente na cultura ocidental cristã, quando Deus expulsa Adão e proibi sua entrada no paraíso.

Os arquitetos, os urbanistas, os paisagistas, o engenheiros, os geógrafos, todos os planejadores do espaço definem, interferem ou inferem nas configurações da cidade: avenidas, ruas, bosques, conjuntos habitacionais, vilas, travessas, becos, logradouros e demais formas de circulação. Restringem os locais, dias e horas onde se pode ou não entrar. Por meio das passarelas, viadutos, faixa de pedestres, corredores, escadas (tudo em nome da segurança), determinam o caminhar dos transeuntes. Os edifícios, os arranha-céus, monumentos, praças, bosques, jardins, formas de arranjo espacial, são estratégias empregadas no afã de vigiar e manter a ordenação espacial e, por conseguinte, o controle social. 
Apesar do desejo do controle do espaço, por parte dos grupos hegemônicos, Lefebvre (2001, p. 7) nos lembra: "nenhuma lei é inteiramente geral é absoluta". Em contraposição as estratégias espaciais institucionalizadas, se materializam, por meio das práticas sociais, o espaço vivido. Este é considerado por Almeida (2003, p.72), "como campo atravessado de valores ligados à maneira como os indivíduos apreendem o meio ambiente e entram em relação com ele".

Frente às perspectivas de controle espacial, restam os caminhantes e andarilhos a utilização de táticas, que invertam a ordem estabelecida para consumo do espaço. "Caminhar não é preciso, andar é preciso". Não caminhar na passarela e criar desvios e corporificar os espaços proibidos. O espaço vivido se constitui na apropriação dos espaços percebidos e concebidos, por meio de práticas desviantes.

Essa capacidade desviante e inventiva dos sujeitos andantes é aprofundada por De Certeau (2001, 2002). Apesar das estratégias de controle espacial o ser ordinário, o homem comum é um ser inventivo, criativo e bricoleiro, tem capacidade de recriar jogos espaciais. Segundo o teórico do cotidiano,

Os jogos dos passos moldam espaços. Tecem lugares. Sob este ponto de vista, as motricidades dos pedestres formam um desses sistemas reais cuja existência faz efetivamente a cidade, mas não têm nenhum receptáculo físico. Elas não se localizam, mas são elas que especializam. (2001, p. 176).

O homem comum, por meio das práticas cotidianas: fazer, caminhar, falar, vestir, comer, trabalhar, andar, conversar, desviar, reinventa formas de apropriação dos espaços interditos, por meio de novos objetos e ações que não foram pensadas e, portanto não podem ser controladas. $\mathrm{O}$ que as ciências parcelares (LEFEBVRE, 1991) entendia como alienação é, nas abordagens culturais, compreendido como inventividade, criatividade, resistência e desvio contra as formas de imposições institucionalizadoras de poder, presentes nos espaços percebidos e concebidos.

\section{A CIDADE: PALIMPSESTO DAS PRÁTICAS SOCIAIS}

A análise da cidade apreendida como espectro social irá promover a interdependência e interconectividade entre espaço percebido, concebido e vivido. Simultaneamente essas dimensões do espaço social vão se materializar nas práticas de inclusão (isotopia), de exclusão (heterotopia), as quais são formadoras de espacialidades.

A apropriação da teoria Lefebvriana como pressuposto interpretativo implica pensar sobre quais locais na cidade são constituídos por meio da lógica dos espaços percebidos, concebidos e vividos. Não existe um espaço organizado por uma lógica especifica, no entanto, a partir de sua gênese a tríade espacial será pensada ora para atender uma, ora outra demanda econômica e social.

As relações sociais de troca ou apropriação podem subverter a forma como determinado espaço foi concebido, por intermédio das práticas desviantes, ou seja, atos, atitudes, comportamentos e pensamentos que fogem a lógica capitalista de mercado.

Na obra "La révolution Urbaine" (1970), "A revolução urbana" (2008), Lefebvre realiza a análise dialética sobre o espaço da rua. Ampliamos esse exercício cognitivo para a compreensão da cidade como espaço dos sentimentos de isotopia e heterotopia, por meio da argumentação a favor e contra a cidade, como espaço tanto de controle quanto de possibilidades desviantes.

A cidade é o palco das vivencias coletivas. É o lugar por excelência dos encontros. Segundo Sartre (1968 Situações I), "não é em nenhum refúgio que nos descobriremos: é na rua, na cidade, no meio da multidão, coisa, entre as coisas, homem entre os homens". Sem a configuração do espaço-cidade, não seria possível encontros nas praças, bares, shoppings, passeatas, teatros, hotéis, igrejas, parques, salões, restaurantes, shows, templos, exposições, rodeios, procissões. Estes lugares e atividades animam a cidade e são favorecidos por sua animação.

Pensar a cidade a partir de elementos fundantes como o econômico ou político é uma idéia, sem dúvida, muito recente. Como afirma Hillman (1993, p. 43), “desde o inicio, o propósito da 
construção de uma cidade foi algo instintivo nos seres humanos: querer estar junto, imaginar, falar, fazer e trocar". E hoje, mais que antes para ver.

$\mathrm{Na}$ cidade, mais que platéia cada indivíduo se torna ator e espectador simultaneamente. A cidade é o espaço privilegiado da visão. No centro da cidade todos olham e são vistos. As vitrines com seus enleios e promoções aproximam o fetiche da mercadoria do sonho possível. As pessoas compram, consomem e transportam desejos em forma de objetos. Os transeuntes são transformados em manequins móveis. Como no sonho de Carlo Collodi, "Pinóquio" ganha vida na versão moderna.

A cidade ultrapassa a função demonstrativa do desejo. Ela possui também as funções informativa, simbólica, educativa e lúdica. Nela se joga, se aprende e se representa. Formada de ordem e segurança a cidade vive, informa, surpreende e educa. De acordo com Cavalcanti (2001, p. 23), a "cidade é educadora: ela educa, ela forma valores, comportamentos, ela informa com sua espacialidade, com seus sinais, com suas imagens, com sua escrita".

$\mathrm{O}$ centro da cidade é o espaço que fornece a segurança sonhada contra a violência física e sexual, vivenciada no espaço da casa, da fábrica, do escritório e da escola, enfim nos espaços heterotópicos. Quanto mais amplo e ocupado por pessoas o espaço estiver, menor a possibilidade de atos violentos, o olhar panótico de cada um, de outrem e de todos garantem a integridade do grupo social. "Sorria, você está sendo filmado", presente nos locais fechados e cada vez mais nos locais públicos, é advertência eficaz contra os atos abusivos.

A cidade, como não poderia deixar de ser, é o palco das manifestações, revoluções, algazarras, festas e devaneios. Nela os grupos sociais têm direito a voz, as reivindicações e expressão de liberdade. A cidade murmura, fala, grita e se agita. Estudantes, trabalhadores, políticos, mulheres, negros, grevistas, evangélicos, índios, ciganas, homossexuais, sem-terra, sem-tetos, protestantes, hippes, lunáticos, músicos, poetas e profetas escrevem e inscrevem suas palavras nos ares, nos muros, nas ruas, nas paredes, nos ouvidos, nos corações e nas mentes dos caminhantes e andarilhos. A cidade expele do seu útero signos falantes.

Lugar do encontro, eis a primeira caracterização da cidade. Sim! Mas que tipo de encontro!? O superficial, efêmero, fugaz e fugidio. Na cidade os caminhantes estão em posições opostas. Quando as pessoas se esbarram frente a frente, o tempo do encontro é reduzido a uma rápida saudação ou pedido de desculpa quase inaudível. A dinâmica acelerada do ir e vir atropela atitudes acolhedoras, que necessitam para acontecer do tempo devagar, do deixar acontecer.

Nas viagens de ônibus, trem, aviões, mesmo sentadas lado a lado, as pessoas percorrem distâncias quilométricas sem se dirigirem a palavra. A presença do outro ao lado é experenciada com estranhamento. Cada um se fecha no seu livro, no filme, na revista, com sua música, com suas lembranças a fim de que o outro perceba que sua presença não é bem quista. Nos espaços da cidade, como no romance de Scliar (1999), "somos um exército, exercito de um homem só".

Vitrines ambulantes, cada indivíduo deseja mostrar mais que possui. O consumo exacerbado, roupas, alimentos, objetos, prazeres e corpos, se justificam pela aparência. O carro do ano; o apartamento duplex de cobertura; a roupa de griffe; os restaurantes luxuosos; as jóias, os perfumes e os acessórios caríssimos delimitam o tato, encantam o olhar, "refinam" o olfato e paladar, abrem portas, marcam os acentos, determina os espaços. Mercadorias aprisionadas e aprisionantes dos sentidos e da vida. Na cidade a aparência, nada mais! Rede organizadora do e para o consumo eis a síntese da cidade.

A cidade é desinformativa, não-simbólica e não-lúdica. A rapidez, o tumulto e o barulho sufocam a fala, ensurdece os ouvidos e não permitem a comunica-Ação entre os falantes. As informações são secretadas, os símbolos e signos se escondem sob tocaias. Para os analfabetos, caminhar pela cidade é andar às cegas. Não saber decodificar os sinais, ler os símbolos e interpretar os significados fervescentes da cidade é se perder no labirinto da selva de pedra sem o fio de Ariadne.

O espaço voltado eminentemente ao trabalho, produção de bens, mercadorias e produtos e prestação de serviços, a cidade é transformada na negação do lúdico, da brincadeira, da gargalhada, 
do estar à toa, sentar na praça com os amigos, a pelada no fim de tarde, jogar conversa fora, olhar e sentir a vida passar.

É obvio que o lúdico é permitido; desde que realizado nos espaços controlados e mercantilizados, as lan house, os shoppings, a Disneylândia, os parques temáticos, o turismo ecológico (se isso é possível), o city tour, as casas de jogos, as salas de cinemas, as "baladas", os motéis, os shows, as exposições agropecuárias, o teatro, o carnaval, as micaretas, o futebol, os campeonatos, as olimpíadas espaços de práticas sociais concebidos para o "encontro", o "prazer" e "liberdade". O dinheiro é a senha de entrada para o "riso" e "alegria".

O comércio do entretenimento, do lúdico e da alegria incentivado, controlado e vigiado em beneficio do capital. No retorno a casa, ao escritório, à fábrica, à faculdade, ao trânsito, ao trabalho, espaços do não-lúdico, o sentimento de tédio, stress, depressão solidão e angústia se intensificam.

Nesse contexto resta o refúgio para a "natureza". De acordo Hillman (1993, p. 37), "uma das fantasias favoritas da humanidade é a de que a alma perto da natureza vive melhor e, portanto, necessita diminuir seu ritmo para encontrar o da natureza, pois na cidade a alma se torna sofisticada e corrompida". Citadinos esperam ansiosamente pelo fim-de-semana. Os feriados prolongados são esperados como bálsamos, pois a fuga da cidade está garantida. Na segunda-feira, o sentimento de euforia, como passe de mágica, desaparece. Inesperadamente a ausência do inexplicável se apropria dos espíritos debilitados.

O centro da cidade é o espaço do medo e insegurança. Nenhum cuidado é infalível contra o assalto, o golpe, a violência (às vezes praticada por aqueles que deveriam zelar pela segurança). Na cidade não é possível se diferenciar o bandido do mocinho. Quanto mais aberto o espaço, menor a possibilidade de segurança. "Tá lá um corpo estendido no chão”, o menino de rua cheira cola, o desempregado rouba um pão é baleado pela polícia, a vendedora de bala no sinal é ignorada, a mãe com bebê no colo pede esmola, o pederasta assedia a criança no portão da escola. Mas nos espaços fechados não é diferente, as drogas atravessam os portões gradeados do colégio, um psicopata entra na sala de cinema e metralha as pessoas, assaltos nos ônibus e residências. Ninguém se comove. Ninguém se responsabiliza, ninguém se compromete. Todos fingem que o problema da miséria do outro não é problema de ninguém.

A violência vivenciada nos espaços abertos ou fechados da cidade é reflexo da sociedade terrorista. Segundo Lefebvre (1991, p. 1555),

[...] toda sociedade que comporta, de um lado, a penúria e não-abundancia, e de outro, predominância de uma classe [...], toda sociedade dessa ordem manteve-se pelo duplo meio da persuasão (ideologia) e da opressão (punições, leis, códigos, tribunais, violência preparada para não precisar se servir dela, violência aberta, tropas armadas, polícia e etc.

Violência urbana, violência da cidade, violência na rua são espectros da violência dos modos de produção capitalístico ( GUATTARI e ROLNIK, 1986), que explora e rouba o trabalhador, o trabalho alheio por meio da mais-valia e da coisificação dos sujeitos . A propriedade privada e a exploração do trabalho são os sustentáculos do social. As beneficies do capital, significadas pelos sonhos de consumo, escondem o horror do espaço de "ondas verticais" (DE CERTEAU, 2001).

A cidade é o espaço da revolução abortada. Ela é o lugar por excelência da repressão, do controle e da violência institucionalizada contra toda e qualquer manifestação que ameace a ordem ou abale as estruturas sociais. As avenidas de rápido acesso para os carros, à descentralização dos órgãos de poder, as construções das universidades distantes dos centros urbanos afastam e dificultam a realização das manifestações dos jovens, fase da vida propicia à rebeldia, ao protesto e resistência contra o abuso de poder. Quando elas insistem em acontecer os "aparelhos repressores do Estado" (ALTHUSSER, 1985), sempre em prontidão são acionados. Tropas de choque, bombas de gás lacrimogêneo, interdição das ruas e avenidas, revólveres, bordão, cordão de isolamento, bala "perdida", todas as estratégias podem ser requeridas em nome da manutenção da paz e harmonia da cidade.

Mercator - volume 8, número 17, 2009: set./dez. 


\section{PRÁXIS URBANA: PRÁTICAS DESVIANTES DE ESPACIALIDADES}

Pensar a cidade apenas como espaço das relações harmônicas ou espaços de contradições e diferenciações de classe não é suficiente para a formulação da interpretação totalizante das dinâmicas urbanas. É preciso encontrar o espaço da antítese, para se criar possibilidades de uma nova configuração espacial na cidade. Para tanto Lefebvre propõe o conceito e a atitude de "práxis espacial", como instrumento e tática capaz de materializar o direito à cidade, que segundo o autor implica a: "constituição ou reconstituição de uma unidade espaço-tempo, no lugar de uma fragmentação" (2008, p. 32).

Que caminhos trilhar? Por onde andar afim de que a unidade espaço-tempo seja conquistada? Partimos do pressuposto das práticas desviantes como elemento da antítese entre espaço percebido e concebido. Destarte, os desvios espaciais não são práticas a devir, mas estão presente no cotidiano efervescente da cidade entre os desvios traçados pelos seus caminhantes e andarilhos por meio da apropriação do espaço determinado pelo atores dominantes.

Ao andar pelas cidades, caminhar por suas ruas, avenidas, praças ou bulevares, espaços institucionalizados, o caminhante recria traçados espaçais que fogem a lógica disciplinar. Segundo De Certeau a "retórica pedestre" (2001), se encontra revestida de práticas sociais apesar do controle dos espaços disciplinares. Os movimentos corpóreos criam as espacialidades. Lanches, jogos, fugas, resistências, inventividades, desvios resignificam as lógicas das segregações espaciais. No movimento dialético entre espaço percebido e espaço concebido é recriado o espaço vivido. Este, representa de acordo com Sahr:

[...] uma linha de fuga, em espaço utópico-agenciador, "imaginado" [...], no qual se encontra a função conscientizadora e um grande potencial de resistência. Trata-se de um tipo de espaço onde os moradores podem desenvolver uma linguagem não-alienadora (analítica ou não) que os permitem exprimir e viver os seus verdadeiros anseios. (2007; p. 69).

Não existe a priori um local que possa ser indicado, exclusivamente, como esfera do espaço percebido, concebido e vivido. Este não fica na casa ou vizinhança, onde os indivíduos estabelecem sentimentos topofílicos (TUAN, 1982). O espaço é criação. Logo, ele não é definido por local Y, $\mathrm{X}$, ou $\mathrm{Z}$, mas por relações sociais. $\mathrm{O}$ ambiente da fábrica comporta formas e conteúdos interligados as três esferas de espaço. A escola é simultaneamente espaço de alienação e libertação. A casa, significada como espaço sacrossanto, na visão da cultura ocidental cristã, nunca foi espaço harmônico. Ela comporta relações de isotopias e heterotopias. A comunidade não é o espaço de definição identidária, mas o local do: “jogo das identidades” (HALL, 2005, p. 19). Lugar e o cotidiano são considerados, nas abordagens culturais geográficas, mais próximos ao espaço vivido.

O lugar e cotidiano são espaços-tempos dialéticos. O cotidiano é tempo aprisionante do ser humano, mas também constitui a vitória da subjetividade, que ultrapassa a barreira das práticas repetitivas e se instala como defende Lefebvre, em práxis libertadora, a "práxis espacial". (GOTTDIENER, 1997, p. 126).

A práxis espacial ultrapassa o espaço coisificado e tempo alienado. Assim, o cotidiano é compreendido como espaço e tempo da cotidianidade. Martins afirma, "na cotidianidade, e não na vida cotidiana, [...] a vida se torna um modo de vida marcado por uma sociabilidade teatral, pela representação (por fazer presente o ausente) e pela fabulação" (2000, p. 104).

Cotidianidade, tempo e espaço vivido não se configuram num conjunto alienado de conhecimentos e práticas destituídas de lógica, ao contrário, estão repletos de significados que exigem complexos deciframentos (dupla hermenêutica), a fim de se estabelecer às resignificações espaciais de determinado grupo social.

As vivencias de totalidade no espaço vivido comportam as configurações, complexos, símbolos, fabulações, significados, teatros, narrativas, imaginários, arquétipos, ficções, histórias, realidades e 
sonhos. Para Martins, "cotidianidade [...] é substantivamente a consciência do lugar das contradições na era do cotidiano. Ela é o momento da história que parece dominado pelo repetitivo e pelo que não tem sentido". (2000, p.108).

Cotidianidade e espacialidades são práticas históricas e sociais. Seus significados se materializam nas formas, repletas de conteúdos (símbolos, imaginários, devires, desejos, signos, significados e poiésis). Segundo Lefebvre (1983, p.33),

Aquilo que o desejo trama interfere e se entrelaça com as grades dos lugares e das palavras: o desejo de um com o desejo do outro, o desejo de ser desejado ou de se desejar e o desejo do desejo - as tramas do desejo com os lugares e os não-lugares, com o dito e o não-dito, com o impossível de dizer. O espaço está semeado de signos do permitido e do proibido.

Os conteúdos e formas inferem dialeticamente nas configurações dos espaços. A cidade, enquanto lócus privilegiado das vivencias espaciais está repleta de significações subjacentes nas formas e conteúdos dos espaços: percebido e espaço concebido. Signo, significado e significante são conteúdos do espaço, criados nas relações sociais que os seres humanos estabelecem entre si, a sociedade e natureza. A produção dos sentidos é construção social, assevera Sahr,

[...] as interpretações (sentidos) dos signos reproduzem no espaço uma grande variabilidade de intenções e objetos existentes na sociedade. Mas esta variabilidade não significa que as relações sígnicas são aleatórias e livres. Ao contrário, elas são embutidas em contextos sociais claramente delimitados e localizadas em regiões sociais. $(2007$, p.63)

A busca do entendimento das práticas vivenciadas nas cidades passa pela compreensão de que o espaço não é transcendência, mas construção social, e, portanto geográfica e histórica. O espaço da cidade moderna traz na sua manifestação primeira o selo da objetividade. Mas subjacente à forma se encontra a subjetividade, própria dos desejos, decisões e escolhas das pessoas que se apropriam e fazem com isso viver a cidade. Frémont defende o espaço criação, este: "supõe que ao domínio das limitações matérias se venha juntar o poder de dar vida a uma obra. Esta via difícil tende a substituir o ordenamento do espaço por uma arte do espaço". (1980, p. 251).

A cidade, além do espaço percebido e concebido, passa a ser compreendida também como espaço vivido. Nesta esfera as pessoas estabelecem relações de domínios e apropriações dos bens econômicos e espaciais. Estas relações são conflituosas, pois na essência o espaço é poder (RAFFESTIN, 1993). Eis uma lição básica a ser apreendida nos cursos de formação de geógrafos.

$\mathrm{O}$ espaço da cidade enquanto construção, não se resume ao planejado e determinado pelo poder hegenômico. Para além dessas percepções o espaço é repleto de possibilidades de recriações contidas nas vivências e experiências humanas resignificadas no espaço e mundo vividos, pelo intermédio das práticas de especialidades desviantes. Práticas, especialidades e culturas desviantes são processos que comportam lógicas que fogem a formulação capitalista de valor de uso do espaço.

Como podemos identificar na cidade as práticas desviantes? Nas cidades elas se encontram em tocaia. $\mathrm{O}$ andar, o ato mais comum e corriqueiro do ser humano, é o revelador mor das práticas desviantes. O geógrafo cultural para captá-las caminha entre os transeuntes, caminhantes, passageiros e andarilhos na cidade. Somente uma Geografia Desviante, dos gabinetes, dos laboratórios e das salas de aula das academias, experenciada na esfera do mundo vivido é capaz de ver, ouvir, observar e compreender aquilo que entre atitudes e comportamentos, fazeres, falas e espaços homogeneizados brinca de esconde-esconde nos espaços interditos da cidade.

As práticas cotidianas, (DE CERTEAU, 2001, 2002) andar, comer, dormir, falar, vestir, lavar, ler, acordar, amar, vender, morar, escrever, passear, nascer, morrer, cantar, cuidar, trocar informações, ouvir, cozinhar, comemorar, comprar, nomear coisas, dançar, estudar, reproduzir, imaginar, descansar, orar, pensar, estão prenhes de desvios, caminhos e espaços não coagidos pelo capital. 
Vejamos como algumas dessas práticas se apresentam no cotidiano da cidade. A cidade moderna não foi planejada para o andar, o caminhar, o encontro de pessoas. A cidade idealizada pelos urbanistas é a cidade vazia de pessoas. Hillman certifica,

Vistas das pranchetas dos arquitetos e das plantas dos urbanistas raramente mostram uma multidão. Em vez disso, casais passeiam sob as árvores, pessoas surgem uma de cada vez saídas dos carros estacionados... como se houvesse uma polifobia, medo do muito, medo de encarar e de ser encarado pelos outros.

A cidade moderna foi planejada e é recriada continudamente para a circulação dos carros, não das pessoas. As ruas, e avenidas estão descalçadas. Andar de bicicleta ou caminhar à pé, numa cidade percebida e concebida para o automóvel se transforma numa prática desviante. Se de repente, as pessoas fossem para trabalho, nos encontros, reuniões, nas atividades de lazer, nas escolas, nos supermercados, nas feiras à pé ou de bicicleta, esta prática colocaria em colapso o sistema de transporte interurbano. Sabedores disso os empresários, industriais do ramo investem fortemente em markinting e propaganda, que dão vida ao fetiche do carro do ano, adquirido pela facilidade dos financiamentos. Imaginem! Menos carro, menos poluição, menos guerra pelo petróleo, menos doenças respiratórias, menos roubos, menos agências de seguro, menos IPVA, menos stress, menos acidentes, menos mortes, menos controle do espaço, menos lucro.

A cidade é espaço por excelência dos carros, daqueles que chegam às ruas com a "facilidade" de pagamento em 48 meses, período máximo em que o carro já deve ser trocado por outro, para que o proprietário não tenha "despesas" com manutenção. Ao indivíduo que não tem condições de comprá-lo resta, frente a impossibilidade de andar à pé, o transporte coletivo. Neste, que a priori se apresenta como espaço de controle, é possível experienciar práticas desviantes. O pular a katraca ou passar por baixo da roleta, praticado por crianças e adolescente, descer do ônibus sem pagar a passagem são atitudes desviantes. Quantos milhões de reais os donos de empresas de transporte coletivo deixariam de lucrar por dia se fosse decretado: "movimento passe livre" ou "quebra das katracas"?

Nas praças, jardins, parques, canteiros, bulevares, como em qualquer espaço controlado, as passarelas e as faixas de pedestre indicam o caminho a ser percorrido. É instigante ver entre elas os desvios construídos por meio dos passos caminhantes, silenciosos, incansáveis. Passarelas: imagem do desejo de controle dos corpos transeuntes. Desvios: práticas caminhantes, daqueles que consciente ou inconscientemente, negam a ordem estabelecida.

As práticas desviantes podem ser percebidas em outros espaços. Hora da refeição, servida em casa, restaurante, refeitório ou lanchonete, o que pode ser considerado como prática desviante? Em qualquer desse espaço uma imagem facilmente encontrada é uma garrafa de coca-cola. Não tomar a coca-cola ou qualquer outro refigerante (dessa empresa ou da concorrente), servir água ou suco natural nas horas de refeições levaria a falência uma das maiores empresas norte-americanas do mundo. $\mathrm{O}$ controle do espaço não implica apenas na sua configuração. Ele ocorre também pela implantação de hábitos alimentares . Aparentemente tão inofensivos.

As pessoas que optam conscientemente pelo não uso do telefone movel são falas desviantes. O comércio do celular e seus acessórios: chips, baterias, capas, suportes, modelos de ponta, planos das operadoras com suas promessas de acessabilidade, portabilidade, comodidade e qualidade movimenta milhões na economia brasileira. Se repentinamente as pessoas percebessem que o uso do celular como uma mercadoria superflua, portanto, dispensável as empresas de telefonias entrariam em desenquilibrio infindo .

O trabalho é a força propulsora do espaço percebido. Sem o trabalho, sem a apropriação da mais-valia o capitalismo não teria como se manutenir. Para tanto, de acordo com Harvey há um impulso inerente do sistema em: "colocar toda a mão-de-obra, em todos os lugares, sob a dominaçãodo capital" (2006, p. 117). Diante disso, o espaço percebido organiza o trabalho por meio da seriação, 
divisão social do trabalho, da especialização, horários e escalas de produção, disciplinamento, regras e beneficios. Este espaço tem "efeitos alienadores sobre seus habitantes" (SHAR; 2007, p. 68).

Nesse que se configura com a máxima de espaço controlavél também são experienciadas práticas desviantes. No Brasil, uma prática comum entre os empregados é o "enforcamento" do serviço nos dias que antecedem os feriados das sextas-feiras ou os que sucedem a segunda-feira. Nos chamados feriados prologandos os postos de serviços são esvaziados. O centro urbano nesse período experimenta outra dinâmica. Seu espaço é desocupado em detrimento a espaços que proporcionam vivências nemos controladoras do espaço-tempo. Com o afã de disciplinar tal prática foi criado o ponto facultativo. De forma permitida ou não a falta ao trabalho se constitui em prática desviante ao colocar em xeque-mate o sistema financeiro das empresas .

Outra prática desviante que pode ser observada na configuração do espaço da cidade é a prática do grafite. Diretamente ela não abala as estruturas econômicas do sistema, no entanto, marca uma forma de apropriação do espaço que foge ao disciplinamento espacial. Nos espaços dos muros, paredes, parapeitos, bancos das praças e monumentos públicos o grafiteiro escreve e inscreve nesses locais seus códigos apropriativos do espaço. É impossível olhar seus desenhos e frases enigmáticas e permanecer indiferente a mensagem.

Existem milhares de práticas desviantes experenciadas e vivenciadas em surdina nos espaços públicos e privados. Muitas delas são apropriadas e transformadas pela "força em revolução permanente" (HARVEY, 2006) do capital em cultura de massa. Porém como movimento antitético outras tantas delas são criadas e recriadas sem que o poder panótico as controle.

\section{OLHE, PENSE E NÃO PARE}

A cidade é o palimpestro da vida social materializada nas formas de trocas e apropriações dos espaços percebidos, concebidos e vividos. Para a busca da compreensão da dinamicidade e complexidade dos espaços urbanos a teoria lefebvriana se caracteriza como uma, dentre várias possibilidades de investigação e interpretação geográficas. A ela acrescemos o conceito de prática desviante como possibilidade de apropriação do espaço vivido.

As contribuições teoricas de Lefebvre garantiram ao espaço, e por conseguinte a geografia, as significações que foram esquecidas pelas leituras marxistas ao privilegiarem o aspecto econômico em detrimento dos demais "determinantes" sociais. Ora se o modo de produção determina as relações sociais de produção, essas relações não são dadas a priori, elas acontecem entres sujeitos históricos, situados em determinado espaço, configurado por meio de territorialidades e espacialidades culturais. Nesta perspectiva podemos ampliar a tese marxista: "a história da humanidade é a historia da luta de classe", para: a história da humanidade é a história da luta pela conquista, domínio e controle do espaço.

A sociedade moderna vai se instituir a partir da conquista e do controle da cidade. Espaço por excelência da produção e reprodução das relações de produção do capital. A cidade será percebida e concebida a favor das demandas econômicas capitalísticas. Para além destes espaços instituídos - espaço percebido e concebido - a dinâmica da cidade se faz também por meio do espaço vivido. É neste espaço que a vida acontece todos os dias, a cada instante de forma initerrupta e incessante.

O espaço vivido é por excelência o espaço da vida, onde as relações são vivenciadas cotidianamente. No entanto, essas relações não são apenas harmoniosas, são também conflituosas. Os espaços vividos são dialéticos, múltiplos, diversos, contraditórios, discursivos, rotineiros, históricos, simbólicos, dinâmicos, alienantes e apaixonantes. A lógica que sustenta os espaços vividos é a contra-lógica dos espaços percebidos e concebidos. Nestes a força do poder instituído. Naquele a força da vida, que por meio de práticas desviantes não pode ser controlada totalmente pelas estratégias e conluios dos grupos hegemônicos. Daí advém o mal estar da civilização.

Apreender a cidade por meio da complexidade e dinamicidade dos espaços percebidos, concebidos, vividos e suas práticas desviantes é um desafio tridimensional. Geograficizar a cidade 
é pesquisar, sistematizar espacialidades geográficas, sintetizar culturas, compreender as lógicas dos espaços percebido, concebido e vivido é estar atento é predisposto a múltiplos movimentos: pensar dialeticamente, a partir das proposições científicas, se (en)volver nas vivências cotidianas e práticas sociais, retornar a análise sistematizada a fim de fazer aflorar a riqueza e diversidade das espacialidades humanas, representadas por meio dos arranjos e configurações espaciais presentes na cidade e em qualquer outro espaço social.

\section{NOTAS}

(1) "Tá lá o corpo estendido no chão, em vez de rosto uma foto de um gol, em vez de reza uma praga de alguém e um silêncio servindo de amém". Primeiro verso da música: "De frente pro crime", (1974) de João Bosco e Aldir Blanc. A composição retrata a dinâmica espacial e o sentimento de indiferença frente as práticas de violência vivenciada cotidianamente nas metrópoles. Disponível em: http://cifrantiga3.blogspot.com/2006/07/de-frente-pro-crime.html. Acesso em: 24/10/2008.

(2) Ao relacionarmos a violência da cidade com o modo de produção capitalista não estamos defendendo a idéia de que para extingui-la basta a mudança ou o fim do sistema econômico atual. A violência ultrapassa as formatações econômicas capitalísticas. Ver p. ex. Hillman (1993). Este autor considera a violência vivida nos mais diversos espaços da cidade como fenômeno do pensamento moderno, o qual promoveu a separação entre alma e corpo, mente e coração, mundo das coisas e o mundo da natureza, enfim eliminou a anima presente tem todos os seres e objetos.

(3) A titulo de exemplo vejamos o faturamento mensal das empresas de transporte coletivo na cidade de Goiânia. No mês de março, (2009) segundo dados do SETRANSP, o faturamento total do sistema de transporte coletivo da região metropolitana de Goiânia foi de 20,031 milhões de reais. Desse total, a COOTEGO faturou 4 milhões 492 mil 194 reais 3 centavos, distribuídos de acordo com os seguintes itens: passageiros que passaram pela catraca (4 milhões 1 mil 762 reais); linhas não assumidas (38 mil 831 reais 37 centavos); pontos de conexão (211 mil 600 reais) e venda a bordo (240 mil reais). Fonte Jornal Opção (Goiânia, 17 de abril de 2009). http://www.jornalopcao.com.br/index.asp?secao=Reportagens\&idjornal=81\&idrep=720. Acesso: em 05/04/2009.

(4) A Coca-Cola Brasil anunciou no dia 12/02/2009 um investimento R \$ 1,75 bilhão no País em 2009, o que representa um crescimento de $16,6 \%$ em relação ao ano passado. Esse é o maior investimento da história da empresa no Brasil. A empresa também informou um faturamento de R $\$ 15$ bilhões em 2008, recorde da empresa no País, que representou um crescimento de $25 \%$ em relação ao resultado a 2007. http://www.revista-fi.com/noticias_ler.php?id_noticia=36. Acesso em 15/02/09

(5) Conforme os números apurados pelo Anuário TELECOM 2006, de todos os segmentos de produtos de telecomunicações, o de telefonia móvel foi o que registrou o maior crescimento em 2005 , elevando suas vendas em $62,09 \%$ e atingindo uma receita líquida de pouco mais de US\$2,3 bilhões. http://www.anuariotelecom.com.br/anutel/2006/pdfs/PAG_072_074_PROD_TELEF. Acesso: em 10/04/09

(6) De acordo com Federação do Comércio do Rio de Janeiro: em cada dia parado o setor perde R \$ 4,5 bilhões no país inteiro. Edição do dia 08/04/2009 do Jornal Nacional. http://jornalnacional.globo.com/Telejornais/JN/0,,MUL1079245-10406,00-FIRJA N+FERIADOS+CAUSAM+PREJUIZO+DE+R+BILHOES.html - Acesso em 09/04/2009

\section{REFERENCIA BIBLIOGRÁFICA}

ALMEIDA, Maria Geralda de. Em busca do poético do sertão: um estudo de representações. In: ALMEIDA, Maria Geralda de, e JP RATTS, Alecsandro. (orgs). Geografia: leituras culturais. Goiânia: Alternativa, 2003. ALTHUSSER, Louis. Aparelhos ideológicos do Estado. $7^{\text {a }}$ ed., Rio de Janeiro, 1985.

CASTRO, Iná Elias de. O problema da escala. In: INÁ, Elias de, GOMES, Paulo César da Costa e CORRÊA, Roberto Lobato. Geografia: conceitos e temas. Rio de Janeiro: Bertrand Brasil, 2007.

CAVALCANTI, Lana de Souza. Uma geografia da cidade - elementos de produção. In: CAVALCANTI, Lana de Souza (org). Geografia da cidade. Goiânia: Alternativa, 2001.

CLAVAL, Paul. Geografia e dimensão espacial: a importância dos processos na superfície da terra. In: ALMEIDA, Maria Geralda de, e outros (orgs). Geografia e cultura: a vida dos lugares e os lugares da vida. Goiânia: Vieira, 2008.

DE CERTEAU. Michel et all. A invenção do cotidiano: 1. artes de fazer. $4^{\mathrm{a}}$ ed.. Petrópolis: Vozes, 2001.

DE CERTEAU. Michel A invenção do cotidiano: 2. morar, cozinhar. $4^{\mathrm{a}}$ ed., Petrópolis: Vozes, 2002.

FOUCAULT, Michel. A ordem do discurso: aula inaugural no Collége de France pronunciada em 2 de dezembro de 1970. São Paulo: Loyola, 2000. 
FRÉMONT, Armand. A região, espaço vivido. Coimbra: Livraria Almedina, 1980.

GOTTDIENER. Mark. A produção social do espaço urbano. $2^{a}$ ed. São Paulo: EDUSP, 1977.

GUATTARI, Félix \& ROLNIL, Suely. Micropolítica: cartografias do desejo. Petrópolis: Vozes, 2005.

HALL, Stuart. A identidade cultural na pós-modernidade. 10a ed., Rio de Janeiro, DP\&A, 2005.

HARVEY, David. A produção capitalista do espaço. $2^{\mathrm{a}}$ ed., São Paulo: Annablume, 2006.

HILLMAN, James. Cidade \& alma. São Paulo: Studio Nobel, 1993.

JENKINS, Keith. A história repensada. São Paulo: Contexto, 2001.

LEFEBVRE. Henry. A revolução urbana. Belo Horizonte: Editora UFMG, 2004.

LEFEBVRE. Henry. A vida cotidiana no mundo moderno. São Paulo: Ática, 1991.

LEFEBVRE. Henry. O direito à cidade. São Paulo: Centauro, 2001.

LEFEBVRE. Henry. Lógica formal e lógica dialética. $3^{\text {a }}$ ed., Rio de Janeiro: Civilização. brasileira, 1983.

LEFEBVRE. Henry. Espaço e política. Belo Horizonte: UFMG, 2008.

MARTINS, José de Souza. A sociabilidade do homem simples: cotidiano e história na modernidade anômala. São Paulo: HUCITEC, 2000.

SARTRE, Jean-Paul. Uma idéia fundamental da fenomenologia de Husserl: a intecionalidade. In: Situações I. Lisboa: Publicações Europa-América, 1968.

SARTRE, Jean-Paul. O ser e o nada: ensaio de ontologia fenomenológica. 15a ed., Petropólis: Vozes, 2007. SAHR, Wolf-Dietrich. Signos e espaço mundos - a semiótica da espacialização na geografia cultural. In: KOZEL, Salete et al. (orgs.) Da percepção e cognição a representação: reconstruções teóricas da geografia cultural e humanista. São Paulo: Terceira Margem; Curitiba: NEER, 2007.

SCLAIR, Moacyr. O exército de um homem só. Porto Alegre: L\&PM, 1999.

RAFFESTIN, Claude. Por uma geografia do poder. São Paulo: Ática, 1993.

TUAN, Yi-Fu. Geografia Humanista. In: CHRISTOFOLETTI, Antonio. Perspectivas da Geografia. São Paulo: Difel, 1982.

Trabalho enviado em setembro de 2009

Trabalho aceito em dezembro de 2009

Mercator - volume 8, número 17, 2009: set./dez. 